\title{
Universal primer design for crustacean and bivalve-mollusc authenticity based on cytochrome- $b$ gene
}

\author{
DWIYITNO DWIYITNO ${ }^{1,2, \bullet}$, STEFAN HOFFMAN ${ }^{3}$, KOEN PARMENTIER $^{3}$, CHRIS VAN KEER $^{2}$ \\ ${ }^{1}$ Research and Development Center for Marine and Fisheries Product Processing and Biotechnology. Jl. K.S. Tubun Petamburan VI, Jakarta Pusat 10260, \\ Jakarta, Indonesia. Tel./fax.: +62-21-53650157/58, `email: dwiyitno.brkp@kkp.go.id \\ ${ }^{2}$ KU Leuven Technologie Campus Gent. Gebroeders Desmetstraat 1, Gent 9000, Belgium \\ ${ }^{3}$ Institute for Agricultural and Fisheries Research (ILVO). Ankerstraat 1, Oostende 8400, Belgium
}

Manuscript received: 30 September 2021. Revision accepted: 6 December 2021.

\begin{abstract}
Dwiyitno D, Hoffman S, Parmentier K, Keer CV. 2021. Universal primer design for crustacean and bivalve-mollusc authenticity based on cytochrome-b gene. Biodiversitas 23: 17-24. Fish and seafood authenticity is important to support traceability practices and protect the public from economic fraud and adulteration. Molecular-based techniques of PCR are known as the most common methods for identifying seafood species. Nevertheless, these techniques rely on the appropriate primer set designed to amplify specific DNA fragments on targeted species. For efficiency application on a wide range of species, a universal primer set is more valuable than a specific primer. The present study developed universal primers, especially for identifying crustaceans and molluscs based on the cytochrome $\mathrm{b}$ mitochondrial DNA $(C y t b)$. The initial primer pair of CytBL1/CytBH originally designed for fish species was applicable to amplify the $C y t b$ gene on most selected fish samples, but not for crustacean and mollusc samples. Based on annealing profile, sequence evaluation (92-100\% similarity), and RT-PCR analysis, the universal primer couple of CytBL1C/CytBHW designed in the present study potentially applied to identify crustacean and mollusc samples, especially shrimp and bivalve-mollusc.
\end{abstract}

Keywords: Authenticity, bivalve, molluscs, polymerase chain reaction, sequencing, RT-PCR, universal primer

\section{INTRODUCTION}

Fish and seafood authentication is important, especially when visual identification is difficult to distinguish the species. Species authenticity is also beneficial to prevent mislabeling of food and protect consumers from fraud and adulteration practices (EU Regulation 2013, Ceruso et al. 2020). Specifically, seafood authentication will prevent the public from the risk of food intoxication from toxic species as well as illegal trading of endangered/conserved species or Illegal Unreported Unregulated Fishing (IUUF) practices (Helyar et al. 2014; Cardeñosa et al. 2018; But et al. 2020).

Protein separation by electrophoresis and nucleic acidbased methods are the two practical approaches for fish authenticity identification (Martinez and Friis 2004). However, molecular-based identification showed more effective throughput and has been globally accepted for detecting seafood species, including in food products for quality control and authentication (Rasmussen Hellberg and Morrissey 2011, Horreo et al. 2013). The Fish Barcode of Life Initiative (BOLD), for example, has been developed to facilitate a global taxonomic identification database for animal species, including seafood (Becker et al. 2011).

DNA fragments of mitochondria have been widely used for species identification due to accuracy and sensitivity (Barth et al. 2017). Cyt b, cytochrome oxidase subunit I (COI), and 16S ribosomal RNA (16SrRNA) genes are among the most targeted mitochondrial genes for species identification (Armani et al. 2011; Nicolè et al. 2012; Shokralla et al. 2015; Giusti et al. 2017; Zanzi and
Martinsohn 2017). Fingerprinting techniques (such as RFLP, AFLP, SSCP, RAPD, DGGE), real time-PCR, and sequencing have been employed as alternative tools for evaluating PCR results. Regardless of the appropriate gene target, other factors are crucial for a successful identification based on the molecular method, such as DNA purity, reagent concentration and combination, and polymerase enzyme. The successfulness of species discrimination based on DNA approach including polymerase chain reaction (PCR) and sequencing remarkably rely on the primer couple specificity (Armani et al. 2016).

In order to overcome the limitation of molecular identification with specific primers for a wide range of seafood groups, a universal primer set could be an alternative (Miya et al. 2015; Kim et al. 2019). However, many universal primer couples fail to identify aquatic species (Giusti et al. 2017). This study aimed to design a universal primer couple based on $C y t b$ gene, potentially applicable for crustacean and mollusc-bivalve. To date, there are no applicable universal primers for crustacean and bivalve species designed for $C y t b$ gene, except that for mollusc as reported by Merritt et al. (1998). The $C y t b$ gene shows a high variation of interspecies but low variation among species (Aranishi et al. 2005). This gene has also been successfully applied to identify processed fish species (Cutarelli et al. 2018). 


\section{MATERIAL AND METHODS}

\section{Primer design}

At first, a typical specific primer couple for seafood identification based on $C y t b$ was evaluated for universal primer suitability. We chose the CytBL1/CytBH primer couple, which was designed to amplify the $C y t b$ of fish species (Céspedes et al. 1998). Since our test showed not optimal for crustaceans, mollusc, and some fishes, these primers were modified by introducing some wobbles (Merritt et al. 1998). Multiple alignment analysis was assessed to $C y t b$ genes of selected seafood samples from gene banks (https://www.ncbi.nlm.nih.gov/genbank/) or
FishTrace (https://fishtrace.jrc.ec.europa.eu/) as drawn in Figure 1. The analysis was employed based on the pairwise alignment formula by BioEdit version 5.0.6 (https://bioedit.software.informer.com/5.0/).

We selected three candidates of forwarding primers and a reverse primer as presented in Table 1. Primer couple was designed with Oligo software following several primer design rules (Quellhorst and Rulli 2012). Table 1 summarizes the properties of the designed primers. Selected primer candidates were then synthesized, and the reliability of designed universal primers was confirmed to amplify the same region as the initial primers on selected seafood samples.

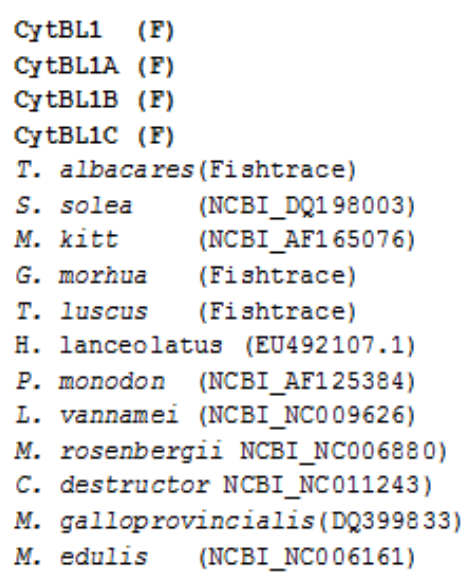

CytBH (R) CytBHW (R)

T. albacares (Fishtrace)

S. solea (NCBI_DQ198003)

M. kitt (NCBI_AF165076)

G. morhua (Fishtrace)

T. Iuscus (Fishtrace)

H. lanceolatus (EU492107.1)

P. monodon (NCBI_AF125384)

L. vannamei (NCBI_NC009626)

M. rosenbergii (NCBI_NC006880)

C. destructor(NCBI NC 011243)

M. galloprovincialis (DQ399833)

M. edulis (NCBI_NC006161)
ССАTCCAACATCTCAGCATGATGAAA

CCWGCWAAYATWWCAACTTTRTGA.A

CCWGCWA.YATWWCAACT TTRTGA.ARR

CCWGCWAAYATWWCAACT TTRTGA.ARGTTTGG

61 CTTCCTACCCCCTCTAATATCTCTGCATGATGAAACTTTGGCTCA 105

61 ..C.C....AG...C.................. 105

71 ..C.CG........C.T...TT.............T 115

61 ..C.CG.C....C...................... 105

61 ..C.CG.T........T.A.T...G...T......T 105

61 ..C.C.............С.TT.............T 105

64 ..C.AG.A.AG......T.AA.T.TG........T.T 108

64 T.G.AG.T..TG.C....T..GA.TCTC....T.......T 108

64 T.A....AT..AG......T..ATTCT.....T...T.T 108

64 A.G.A.T...AAGG.G.....AA.T.T.......... 108

96 T.G..TGT..TGTG..CT.AAAC..C..G...GG......T 140

96 T.G...TGT..TGTA..CT.AAAC..C..G...GG......T 140

\section{TGAGGACAAATAT CATTCT GAGGGG}

TGRGGRCAAATAT CWTTYT GRGGRG

401 CCTGAGGACAAATGTCTTTCT GAGGAGCTACCGTCATTACTAACC 445

$401 \ldots \ldots$. .........................T. 445

411.T....G..G.A.A.A. ...T.A...........T. 455

$401 \ldots \ldots$. . . A. A.................... TT 445

401 .A............................... 445

$401 \ldots$...........A..............T....... 445

404 .T........A..A....G......T..A......TT 448

404 .T......................T.........T 448

$404 \ldots \ldots \ldots$........................ 448

$404 \ldots$...G..........T....T.......A........ 448

446 .T.G..G..G.A.G.A..G.G...T........TA 490

446 .T.G..G..G.A..G.A..G.G...T..A......TA 490

Figure 1. Multiple alignments of the designed primers with $C y t$ bene of selected seafood species. Note: wobbles as Y: T/C; R: G/A; W: A/T

Table 1. Set of primers targeted for the amplification of seafood mitochondrial $C y t b$ gene

\begin{tabular}{|c|c|c|c|c|c|}
\hline Primer code & Sequence (5'-3') & $\begin{array}{c}\text { Poisiion* } \\
\text { (bp) }\end{array}$ & $\begin{array}{l}\text { GC } \\
(\%)\end{array}$ & $\begin{array}{c}\mathbf{T}_{\mathbf{m}} \\
\left({ }^{\circ} \mathbf{C}\right)\end{array}$ & Reference \\
\hline \multicolumn{6}{|l|}{ Initial primer } \\
\hline CytBL1(F) & CСАTCCAACATCTCAGCATGATGAAA & 115 & 42 & 74 & Cespedes (1998) \\
\hline CytBH (R) & ССССTCAGAATGATATTTGTCCTCA & 448 & 44 & 72 & Cespedes (1998) \\
\hline \multicolumn{6}{|l|}{ Modified primer } \\
\hline CytBL1A (F) & CCWGCWAAYATWWCAACTTTRTGAA & 115 & 37 & 66 & This study \\
\hline CytBL1B (F) & CCWGCWAAYATWWCAACTTTRTGAARR & 115 & 37 & 72 & This study \\
\hline CytBL1C (F) & CCWGCWAAYATWWCAACTTTRTGAARGTTTGG & 115 & 40 & 88 & This study \\
\hline CytBHW (R) & CYCCYCARAAWGATATTTGYCCYCA & 448 & 47 & 76 & This study \\
\hline
\end{tabular}

Note: *Based on G. morhua (Fishtrace); Wobble: Y: T/C; R: G/A; W: A/T (Merritt et al. 1998) 


\section{Primer evaluation on seafood samples}

Selected seafood samples for primer evaluation were provided from the North Sea and selected fish markets in Belgium. 5-10 individual fresh samples were pre-identified through morphological features. They included 14 fish species, including rounded fish, flatfish, and smelt fish (sand lances). The evaluation also involved seven crustaceans and six molluscs. The species detail is explained in Table 2. Prior to DNA extraction, samples were cleaned and filleted.

Total DNA was extracted using Wizard Promega purification kit (Promega Corporation 2019). The DNA quality was measured by NanoDrop spectrophotometry (ND-1000) to calculate the absorbance ratio at 260 and 280 $\mathrm{nm}$ according to the manufacturer's instruction (Thermo Scientific 2019). A ratio of $\mathrm{A}_{260 / 280} 1.80-2.00$ is considered pure DNA (Brescia and Banks 2012) and used for further PCR assay.

\section{PCR assay and direct sequencing}

The reliability of the designed primers to amplify the $\sim 357 \mathrm{bp}$ of the $C y t b$ gene was employed by PCR assay. The reaction was performed in a mix composed of $10 \mu \mathrm{L}$ Jump Start RED Taq Ready Mix (Sigma P-0982) containing $10 \mathrm{mM}$ Tris- $\mathrm{HCl} \mathrm{pH} 8.3,50 \mathrm{mM} \mathrm{KCl}, 2 \mathrm{mM}$ $\mathrm{MgCl}_{2}, 0.2 \mathrm{mM}$ of each $\mathrm{dNTP}$, and $0.03 \mathrm{U} / \mu \mathrm{l}$ Taq DNA polymerase. Two $\mu \mathrm{L}$ of each primer $(10 \mathrm{mM})$ and $5-20$ $\mathrm{ng} / 20 \mu \mathrm{L}$ of DNA templates were added to the mix.

Amplification was carried out in a PCR-express thermal cycler (Hybaid) at the condition of five min initiation at $94^{\circ} \mathrm{C}, 35$ cycles of amplification at $94^{\circ} \mathrm{C}$ for 30 sec; $50^{\circ} \mathrm{C}$ for $30 \mathrm{sec} ; 72^{\circ} \mathrm{C}$ for $1 \mathrm{~min}$ and five min final extension at $72^{\circ} \mathrm{C}$ (Richardson et al. 2007). Amplified PCR products were analyzed by agarose gel electrophoresis $2.0 \%(\mathrm{w} / \mathrm{v})$. The amplification reaction was performed at least in triplicates.

Direct sequencing was performed on the optimal DNA fragments in order to ensure the designed primers able to amplify the targeted DNA fragment. Sequence analysis was carried out in an ABI 3730xl DNA analyzer. Sequence chromatograms were viewed and evaluated by using ChromasPro and BioEdit software. The selected sequences were then assembled to analyze the overlapping bases (Tamura et al. 2004).

\section{Real-Time PCR application}

The reliability of designed primers for real-time PCR (RT-PCR) was also evaluated on selected crustacean and mollusc samples using QuantiTech SYBR Green RT-PCR Master Mix. PCR reaction was performed in triplicate of DNA samples in MicroAmp Optical 96-well reaction plates (Roche). The RT-PCR amplification was carried out in a LightCycler $^{\circledR} 480$ (Roche Diagnostics 2006) with the condition of initial activation at $95^{\circ} \mathrm{C}$ for $10 \mathrm{~min}$; $40-50$ cycles at $95^{\circ} \mathrm{C}$ for $10 \mathrm{sec}$, and $45-60^{\circ} \mathrm{C}$ annealing for 20 sec; and $72^{\circ} \mathrm{C}$ elongation for $30 \mathrm{sec}$. The melting points $\left(\mathrm{T}_{\mathrm{m}}\right)$ generated from the melting curve $\left(60-90^{\circ} \mathrm{C}\right)$ were used to discriminate between closely related species.
Table 2. Detail of fish, crustacean, and mollusc samples

\begin{tabular}{ll}
\hline Common name & Scientific name \\
\hline Fish & Gadus morhua \\
Cod & Trisopterus luscus \\
Faneca & Eutrigla gurnardus \\
Grey gurnard & Solea solea \\
Common sole & Microstomus kitt \\
Lemon sole & Scophthalmus maximus \\
Tarbot & Malacoraja senta \\
Smooth skate & Raja clavata \\
Thornback ray & Thunnus sp. \\
Tuna & Ammodytes tobianus \\
Small sandeel & Hyperoplus lanceolatus \\
Great sandeel & - \\
Unknown smelt & \\
Crustacean & Penaeus monodon \\
Giant tiger shrimp & Penaeus latisulcatus \\
King shrimp & Crangon crangon \\
Brown shrimp & Macrobrachium rosenbergii \\
Giant freshwater shrimp & \\
Mollusc & Perna. canaliculus \\
Green mussel & Mytilus edulis \\
Blue mussel & Illex argentinus \\
Illex squid & - \\
Unknown mussel & \\
\hline & \\
\hline
\end{tabular}

\section{Data analysis}

The primer couple's reliability was evaluated based on the annealing profiles, showed by a strong band of targeted $C y t b$ fragment, the variation of annealing temperature, and the similarity index of sequencing analysis. The obtained sequences were identified utilizing the Basic Local Alignment Search Tool/BLAST (www.ncbi.nlm.nih.gov/blast). The similarity was compared to the references/libraries obtained via NCBI Genbank.

\section{RESULTS AND DISCUSSION}

\section{PCR amplification}

The initial primer (CytBL1/CytBH) was employed previously for the identification of tuna species and for flatfish (Céspedes et al. 1998). In the present study, this primer set was suitable to amplify the $C y t b$ fragment of flatfish ( $S$. solea) and rounded fish (T. luscus) and $M$. edulis. On the other hand, multiple fragments were found on H. lanceolatus, A. tobianus, and S. maximus (Figure 2). Further PCR evaluation on crustacean and mollusc samples showed that the amplification was not optimum, especially on P. monodon, Solenocera sp., C. crangon, and M. edulis (Figure 3).

The present study revealed that the initial primer of CytBL1/CytBH couple was not optimal to amplify crustacean and mollusc species. Intense bands of low weight fragments (less than $100 \mathrm{bp}$ ) are seen on the electrophoresis gel indicated non-optimal amplification on those species (Figure 3). It can result from residues of primers, primer dimers, DNA templates, or nucleotides due to inappropriate PCR amplification (Mubarak et al. 2020). 
In order to increase the annealing efficiency of CytBL1 and $\mathrm{CytBH}$ primers on various groups of species, some wobbles were introduced on three forward primers (CytBL1A, CytBL1B, and CytBL1C) and a reverse one (CytBHW). CytBL1A is a base shorter than the initial primer (CytBL1) with wobbles modification on six bases; CytBL1B is a base longer with eight wobble modifications, while the CytBL1C is six bases longer than CytBL1 and consists of 7 wobbles. The forward primer $\mathrm{CytBHW}$ has the same length as the initial primer $(\mathrm{CytBH})$ with a modification of six wobbles (Table 1). To reduce the possibility of misbinding, we only use double wobble, i.e. $\mathrm{Y}(\mathrm{T} / \mathrm{C}), \mathrm{R}(\mathrm{G} / \mathrm{A})$, and $\mathrm{W}(\mathrm{A} / \mathrm{T})$.

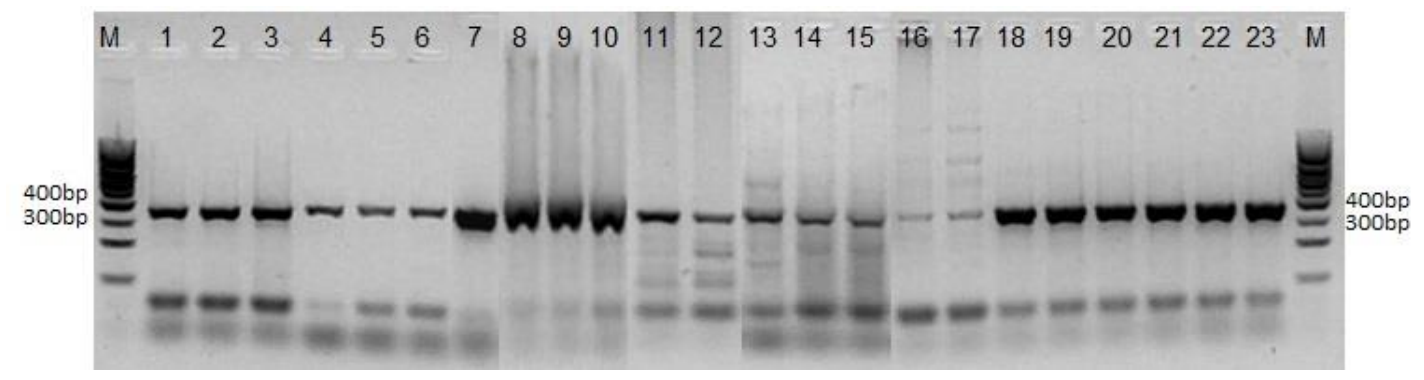

Figure 2. Amplification result of CytBL1/CytBH primers on fish samples. ote: 1-3: S. solea; 4-6: T. luscus; 7: Thunnus sp.; 8-10: G. morhua; 11: H. lanceolatus; 12: A. tobianus; 13-15: S. maximus; 16-17: M. kitt; 18-19: E. gurnardus;20-21: M. senta; 22-23: R. clavata; M: DNA marker

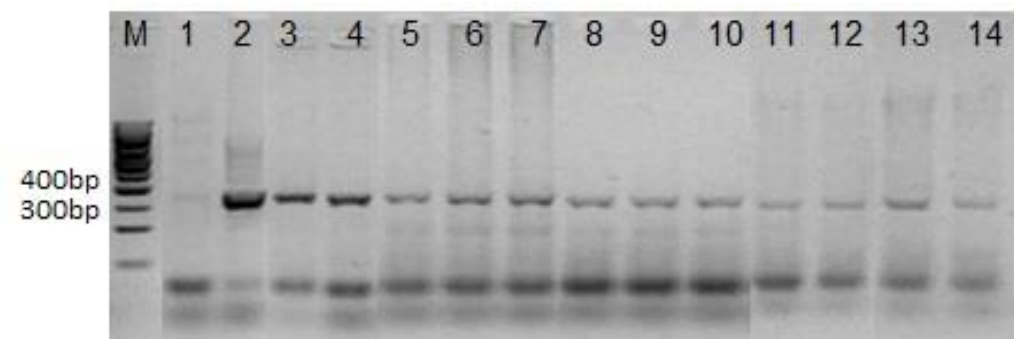

Figure 3. Amplification result of CytBL1/CytBH primers on crustaceans and molluscs. Note: 1: P. monodon; 2: Solenocera sp.; 3-4: P. latisulcatus; 5-7: C. crangon; 8-10: M. edulis; 11-12: Perna canaliculus; 13-14: Illex argentinus; M: DNA marker

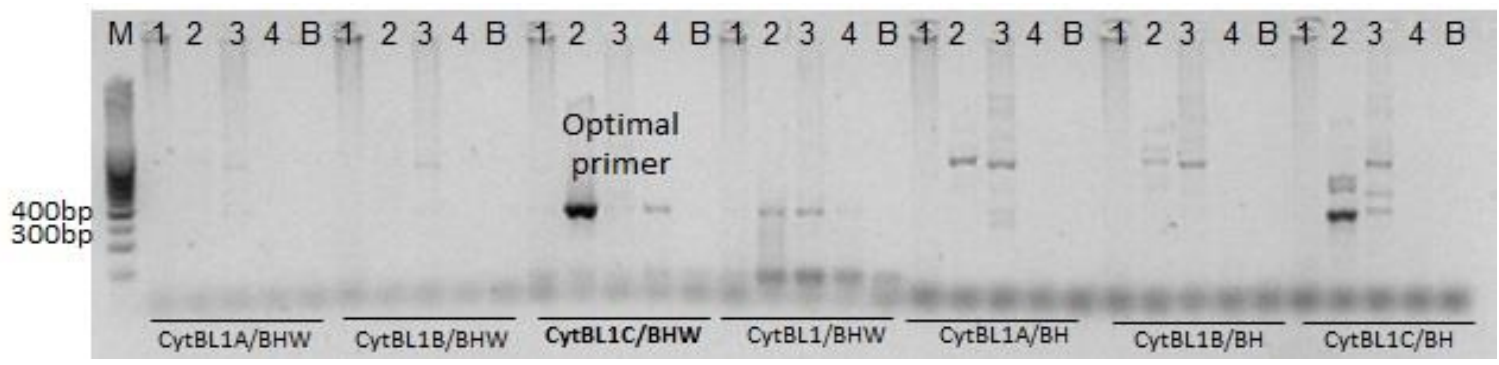

Figure 4. Amplification result of the degenerate primers on selected samples. Note: 1: C. crangon; 2: M. edulis; 3: M. kitt; 4: T. luscus; M: DNA ladder 100bp; B: Blank

Evaluation of designed primers (CytBL1C and CytBHW) on selected samples (C. crangon, M. edulis, $M$. kitt, and T. luscus) showed that a combination of these primers showed the most optimum result, mainly on $M$. edulis (Figure 4). However, further evaluation on the different fish species showed this primer couple failed to produce a single band on the samples, except $S$. maximus. Reducing a base on CytBL1A may reduce the primer specificity, while the double wobbles (RR) may also produce a lower priming efficiency on CytBL1B. The relatively low GC content $(<40 \%)$ may also contribute to reducing the priming efficiency of CytBL1A and CytBL1B (Mallona et al. 2011).

The further evaluation of CytBL1C and CytBHW showed the primer set effectively amplified crustacean samples of $P$. monodon, P. latisulcatus, Solenocera sp., and M. rosenbergii (Figure 4). A similar result was performed on mollusk samples of M. edulis, Perna canaliculus, and unknown mussel samples. Not only was it performed by a single strong band on electrophoresis result, but a relatively wide range of annealing temperature $\left(45-60^{\circ} \mathrm{C}\right)$ indicates that the designed primer is effective for targeted species. 
However, the primer set produced a smeared band on $C$. crangon, suggesting the amplification was not optimal for this particular species (Lorenz 2012; Mubarak et al. 2020).

\section{Sequencing evaluation}

The sequencing analysis on selected samples was also attempted to evaluate primer effectiveness for species identification by assessing the similarity index compared to the online references. Sequence results proved that the designed primer couple effectively amplified the desired DNA fragment of 356-358 bp of $C y t b$ region. Further BLAST analysis showed various similarity indexes between $92 \%$ (M. rosenbergii) and $100 \%$ (L. vannamei and M. edulis) as presented in Table 3. Pearson (2013) suggested that more than $80 \%$ of identity is accepted as significant similarity in sequence analysis.

Identities between 98 and $100 \%$ were obtained from BLAST analysis, indicating the designed primers produced species-species specific discrimination to differentiate between selected crustaceans and mollusc samples. However, BLAST analysis of $M$. rosenbergii showed a relatively low similarity $(92-93 \%)$ to NCBI database. This result could be associated with the fact that genus Macrobrachium has shown high genetic divergence, especially between eastern and western species of IndoPacific origin ( $\mathrm{Ng}$ and Wowor 2011). Another reason might relate to the limitation of the available reference as a comparison. So far, there is no available reference of partial $C y t b$ gene either from NCBI or other sources. The only available reference is a complete mitochondrial genome from NCBI (Li et al. 2019). Therefore, the present study's sequence is the first reported partial $C y t b$ gene of M. rosenbergii.

BLAST analysis on unknown mussels identified similarly $(100 \%)$ as M. edulis and M. galloprovincialis. This double identity could be explained that $M$. edulis and M. galloprovincialis are known as closely related taxa due to either hybridization within the species or doubly uniparental inheritance (Skibinski et al. 1994). This phenomenon results in heteroplasmy in sea mussels that hamper their interspecific divergences (Hilbish et al. 2000). This result indicates the designed primers could identify the variation of closely related species.

Sequencing test of Thunnus sp. sample with CytBL1/ CytBH primer produced a $99 \%$ similarity as T. albacares based on NCBI databank (Table 3). Additionally, BLAST analysis of the CytBL1C/CytBHW primer set was able to differentiate between two unknown shrimps, i.e. the shrimp-1 was identified as $M$. rosenbergii (92\%), and the shrimp-2 was identified as L. vannamei (100\%) in comparison to the gene bank of NCBI. Meanwhile, all unknown mussels were identified with the same primers as M. edulis, whereas the mussel-2 was also recognized as $M$. galloprovincialis.

\section{Real-Time PCR analysis}

RT-PCR analysis was carried out to discriminate between different species based on their melting temperatures $\left(\mathrm{T}_{\mathrm{m}}\right)$. Figure 5A-B shows that RT-PCR was applicable to differentiate selected crustacean and mollusc species. RT-PCR with CytBL1C/CytBHW primer set could differentiate two crustaceans $(P$. monodon and $P$. latisulcatus), and two mussels (M. edulis and Perna canaliculus). In the present study, we evaluated the initial CytBL/CytBH primers for the RT-PCR amplification of fish species between G. morhua and Thunnus sp., as presented in Figure 5C.

The RT-PCR quantitation cycle $(C q)$ was achieved between 20-30 cycles out of 50 cycles, except for crustacean (30-40 cycles). The melting temperature $(\mathrm{Tm})$ variation among different species was between 82.48 and $86.37^{\circ} \mathrm{C}$ for selected fish samples, while for crustacean and mollusc were $78.71-83.54^{\circ} \mathrm{C}$ (Table 4). A different Tm of shrimp species was reported by Sharma et al. (2020) on an HRM RT-PCR study with SYBR Green-I dye i.e. between 71 and $76^{\circ} \mathrm{C}$. Nevertheless, GC content of 3 samples $(M$. senta, Perna canaliculus, and P. latisulcatus) could not be evaluated as the sequencing analysis was not conducted on these samples.

Table 3. Sequencing analysis of selected samples

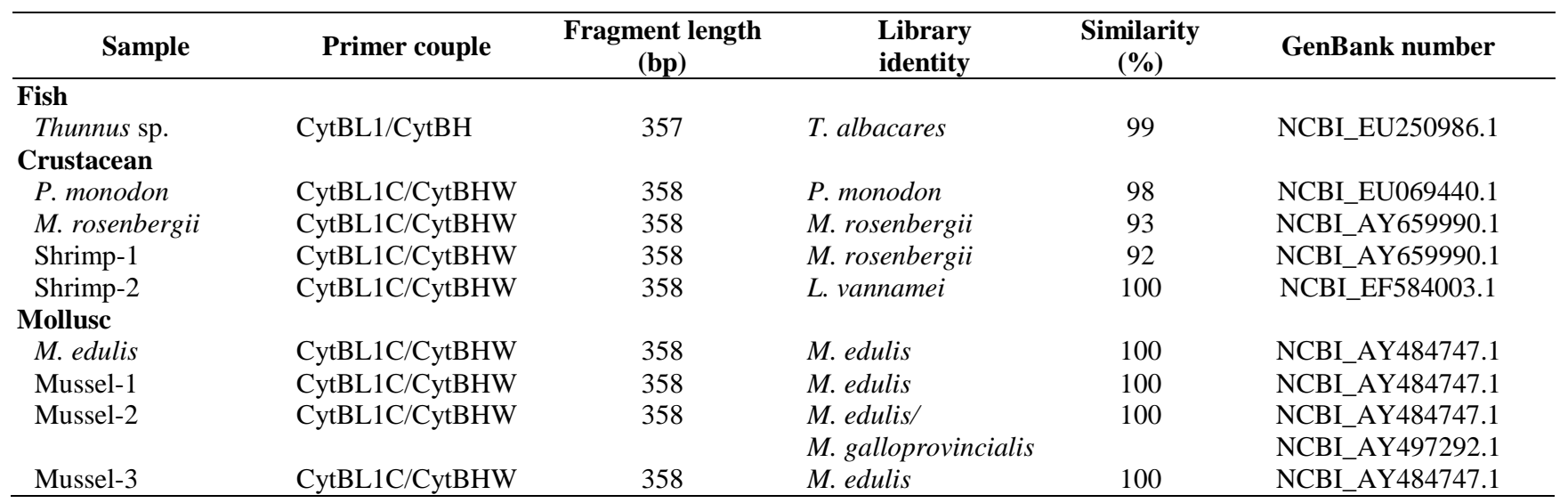




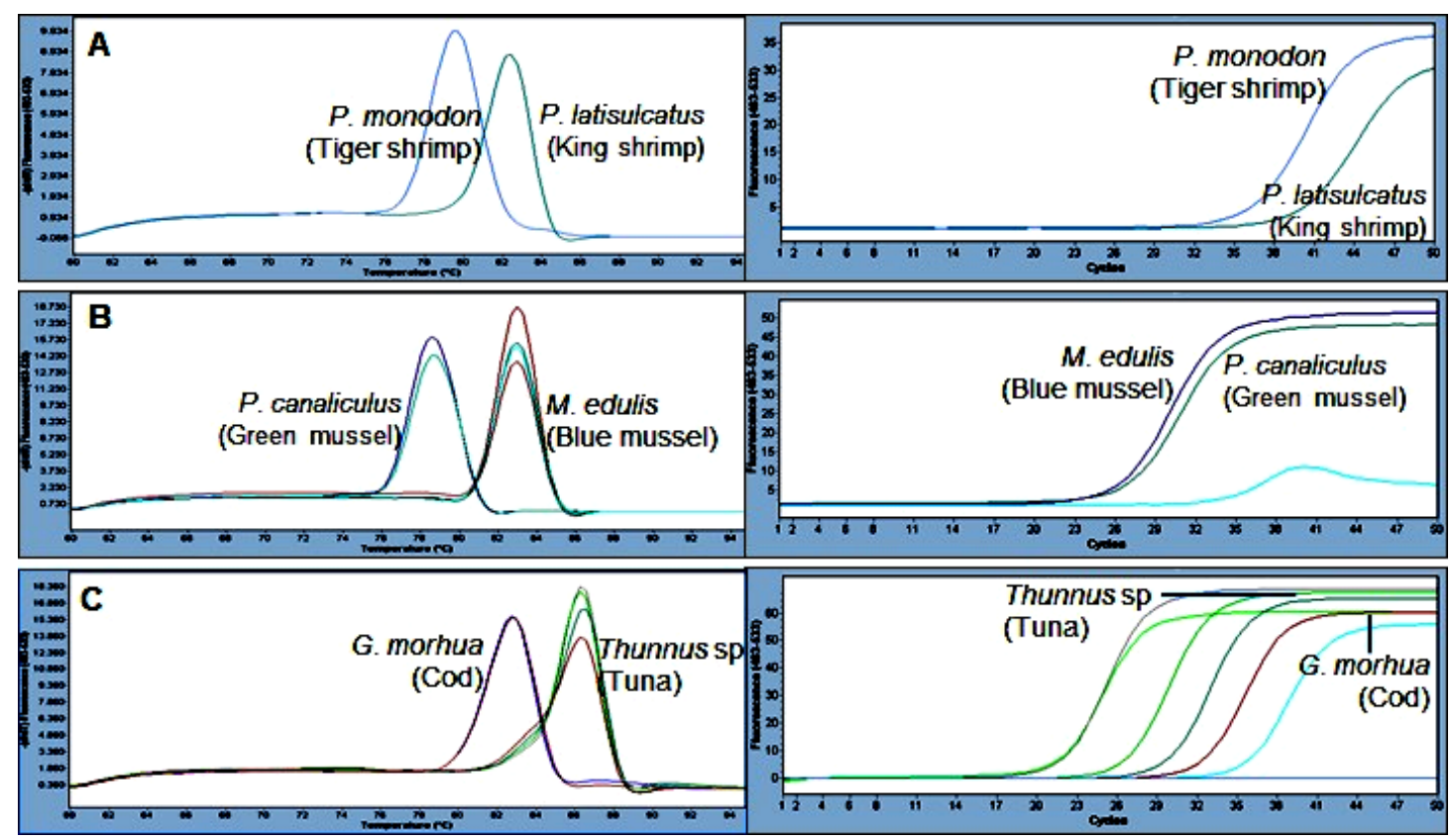

Figure 5. Variations of melting peak (left) and fluorescent history (right) of RT-PCR on samples of crustacean (A), mollusk (B), and fish $(\mathrm{C})$

Table 4. Variations of melting point and GC content of selected samples

\begin{tabular}{llcc}
\hline \multicolumn{1}{c}{ Sample } & \multicolumn{1}{c}{ Primer couple } & $\mathbf{T}_{\mathbf{m}}\left(\mathbf{(}^{\mathbf{0}} \mathbf{C}\right) \boldsymbol{*}$ & GC content $(\boldsymbol{\%})$ \\
\hline G. morhua & CytBL1/CytBH & $82.48-82.78$ & 40 \\
M. senta & CytBL1/CytBH & 83.93 & N/A \\
R. clavata & CytBL1/CytBH & $85.81-86.01$ & 44 \\
Thunnus sp. & CytBL1/CytBH & $86.15-86.37$ & 48 \\
$P$. canaliculus & CytBL1C/CytBHW & $78.71-78.81$ & N/A \\
P. monodon & CytBL1C/CytBHW & 79.66 & 37 \\
P. latisulcatus & CytBL1C/CytBHW & $82.37-82.40$ & N/A \\
M. edulis & CytBL1C/CytBHW & 83.03 & 43 \\
Mussel-M1 & CytBL1C/CytBHW & $83.00-83.23$ & 43 \\
Mussel-M2 & CytBL1C/CytBHW & $82.68-83.54$ & 43 \\
Mussel-M3 & CytBL1C/CytBHW & $82.86-83-34$ & 43 \\
\hline
\end{tabular}

RT-PCR analysis showed that the designed primers (CytBL1C/CytBHW) successfully differentiate the selected crustacean and mussel samples. A similar result was performed on the initial primer of CytBL1/CytBH on selected fish species i.e. between G. morhua and Thunnus sp. and between $R$. clavata and M. senta as performed by significant different of melting temperature profile (Figure 5). The melting point difference of approx. $1^{\circ} \mathrm{C}$ is sufficient to discriminate among different species. A single peak of each melting curve indicates the applicability of the designed primers for RT-PCR analysis and successfully amplified a single targeted DNA fragment (Taylor et al 2017). The fact of annealing efficiency was also indicated by the $C q$ value between $20-30$ cycles. This result is comparable to other studies on RT-PCR assay of penaeid shrimps with a Cq value of 17-30 (Sharma et al. 2020). In general, $\mathrm{T}_{\mathrm{m}}$ profiles of selected samples (Table 4) correspond to their "GC" contents, as the more GC, the higher the melting temperature is (Bonab et al. 2015; Mubarak et al. 2020).
RT-PCR has many advantages for species identification, such as higher sensitivity and specificity, rapid analysis, and direct identification compared to conventional PCR. However, only limited studies reported RT-PCR application for seafood identification, mainly based on the mitochondrial gene. RT-PCR has been applied for fish authentication on 16SrRNA of tuna species (Liu et al. 2016), salmon and trout (Feng et al. 2017), penaeid shrimp (Sharma et al. 2020), as well as European sole on ITS-1 fragment (Herrero et al. 2012). Therefore, the present study would be the first RT-PCR application on crustacean and mollusc identification based on $C y t b$ gene.

\section{ACKNOWLEDGEMENTS}

This study was supported by ILVO-Fisheries Department, Oostende-Belgium. DD and SH are the main contributors to this paper. 


\section{REFERENCES}

Aranishi F, Okimoto T, Ohkubo M, Izumi S. 2005. Molecular identification of commercial spicy pollack roe products by PCRRFLP analysis. J Food Sci 70 (4): 235-238. DOI: 10.1111/j.13652621.2005.tb07165.x.

Armani A, Giusti A, Guardone L, Castigliego L, Gianfaldoni D, Guidi A. 2016. Universal primers used for species identification of foodstuff of animal origin: Effects of oligonucleotide tails on PCR amplification and sequencing performance. Food Anal Methods 9 (5): 1199-1209. DOI: $10.1007 / \mathrm{s} 12161-015-0301-9$.

Armani, Andrea, Castigliego L, Tinacci L, Gianfaldoni D, Guidi A. 2011. Molecular characterization of icefish, (Salangidae family), using direct sequencing of mitochondrial cytochrome $\mathrm{b}$ gene. Food Control 22 (6): 888-895. DOI: 10.1016/j.foodcont.2010.11.020.

Barth JMI, Damerau M, Matschiner M, Jentoft S, Hanel R. 2017. Genomic differentiation and demographic histories of Atlantic and Indo-Pacific yellowfin tuna (Thunnus albacares) populations. Genome Biol Evol 9 (4): 1084-1098 DOI: 10.1093/gbe/evx067.

Bartlett SE, Davidson WS. 1991. Identification of Thunnus Tuna species by the polymerase chain reaction and direct sequence analysis of their mitochondrial cytochrome b genes. Can J Fish Aquat Sci 48 (2): 309 317. DOI: $10.1139 /$ f91-043.

Bonab MM, Alimoghaddam K, Talebian F, Ghaffari SH, Ghavamzadeh A, Nikbin B, Discher DE, Janmey PA, Wang YL, Wagner W, Horn P, Castoldi M, Diehlmann A, Bork S, Saffrich R, Benes V, Blake J, Pfister S, Eckstein V, O'Shea KS. 2015. Real-time PCR handbook. Lab Chip 4 (2): 189-200.

Brescia PJ, Banks P. 2012. DNA Quantification using Gen5 ${ }^{\mathrm{TM}}$. BioTek, 113. www.biotek.com. [6 March 2021]

Bugoni L, Krause L, Petry MV. 2001. Marine debris and human impacts on sea turtles in Southern Brazil. Mar Pollut Bull 42 (12): 1330-1334. DOI: 10.1016/S0025-326X(01)00147-3.

But GWC, Wu HY, Shao KT, Shaw PC. 2020. Rapid detection of CITESlisted shark fin species by loop-mediated isothermal amplification assay with potential for field use. Sci Rep 10 (1): 4455. DOI: 10.1038/s41598-020-61150-8.

Cardeñosa D, Quinlan J, Shea KH, Chapman DD. 2018. Multiplex realtime PCR assay to detect illegal trade of CITES-listed shark species. Sci Rep 8: 16313. DOI: 10.1038/s41598-018-34663-6.

Ceruso M, Mascolo C, De Luca P, Venuti I, Smaldone G, Biffali E Anastasio A, Pepe T, Sordino P. 2020. A rapid method for the identification of fresh and processed Pagellus erythrinus species against frauds. Foods 9 (10): 1-15. DOI: 10.3390/foods9101397.

Céspedes A, García T, Carrera E, González I, Sanz B, Hernández PE, Martí R. 1998. Identification of flatfish species using polymerase chain reaction (PCR) amplification and restriction analysis of the cytochrome b gene. J Food Sci 63 (2): 206-209. DOI: 10.1111/j.13652621.1998.tb15710.x.

Chavali S, Mahajan A, Tabassum R, Maiti S, Bharadwaj D. 2005. Oligonucleotide properties determination and primer designing: A critical examination of predictions. Bioinformatics 21 (20): 3918 3925. DOI: 10.1093/bioinformatics/bti633.

Chen TY, Shiau CY, Noguchi T, Wei CI, Hwang DF. 2003. Identification of pufferfish species by native isoelectric focusing technique. Food Chemistry 83 (3): 475-479. DOI: 10.1016/S0308-8146(03)00253-X.

Cutarelli A, Galiero G, Capuano F, Corrado F. 2018. Species identification by means of mitochondrial cytochrome b DNA sequencing in processed anchovy, sardine and tuna products. Food Sci Nutr 9 (4): 369-375. DOI: 10.4236/fns.2018.94029.

De Bruyn M, Wilson JC, Mather PB. 2004. Reconciling geography and genealogy: Phylogeography of giant freshwater prawns from the Lake Carpentaria region. Mol Ecol 13 (11): 3515-3526. DOI 10.1111/j.1365-294X.2004.02348.x.

European Parliament and Council of the European Union. 2013. Regulation (Eu) No 1379/2013 Of The European Parliament And of the Council of 11 December 2013 on the common organization of the markets in fishery and aquaculture products, amending Counci Regulations (EC) No 1184/2006 and (EC) No 1224/2009 and repealing. Official J Eur Union L354 (28.12.2013): 1-21.

Feng J, Wu Z, Xie X, Dai Z, Liu S. 2017. A real-time polymerase chain reaction method for the identification of four commercially important salmon and trout species. Mitochondrial DNA A DNA Mapp Seq Anal 28 (1): 104-111. DOI: 10.3109/19401736.2015.1111346.
Giusti A, Tinacci L, Sotelo CG, Marchetti M, Guidi A, Zheng W, Armani A. 2017. Seafood identification in multispecies products: Assessment of 16SrRNA, cytb, and COI universal primers' efficiency as a preliminary analytical step for setting up metabarcoding nextgeneration sequencing techniques. J Agric Food Chem 65 (13): 29022912. DOI: 10.1021/acs.jafc.6b05802.

Hebert PDN, Cywinska A, Ball SL, DeWaard JR. 2003. Biological identifications through DNA barcodes. Proc Royal Soc B: Biol Sci 270 (1512): 313-321. DOI: 10.1098/rspb.2002.2218.

Helyar SJ, Lloyd AD, De Bruyn M, Leake J, Bennett N, Carvalho GR. 2014. Fish product mislabelling: Failings of traceability in the production chain and implications for Illegal, Unreported and Unregulated (IUU) fishing. PLoS One 9: e098691. DOI: 10.1371/journal.pone.0098691.

Herrero B, Lago FC, Vieites JM, Espiñeira M. 2012. Real-time PCR method applied to seafood products for authentication of European sole (Solea solea) and differentiation of common substitute species. Food Addit Contam Part A Chem Anal Control Expo Risk Assess 29 (1): 12-18. DOI: 10.1080/19440049.2011.623682.

Hilbish TJ, Mullinax A, Dolven SI, Meyer A, Koehn RK, Rawson PD. 2000. Origin of the antitropical distribution pattern in marine mussels (Mytilus spp.): Routes and timing of transequatorial migration. Mar Biol 136 (1): 69-77. DOI: 10.1007/s002270050010.

Horreo JL, Ardura A, Pola IG, Martinez JL, Garcia-Vazquez E. 2013. Universal primers for species authentication of animal foodstuff in a single polymerase chain reaction. J Sci Food Agric 93 (2): 354-361. DOI: $10.1002 /$ jsfa.5766

Hubalkova Z, Kralik P, Tremlova B, Rencova E. 2007. Methods of gadoid fish species identification in food and their economic impact in the Czech Republic: A review. Veterinarni Medicina 52 (7): 273-292. DOI: 10.17221/2044-VETMED.

Ivanova NV, Zemlak T, Hanner RH, Hebert PDN. 2007. Universal primer cocktails for fish DNA barcoding. Mol Ecol 7 (4): 544-548. DOI: 10.1111/j.1471-8286.2007.01748.x.

Jordan LG, Steele CA, Thorgaard G H. 2010. Universal mtDNA primers for species identification of degraded bony fish samples. Mol Ecol Resour 10 (1): 225-228. DOI: 10.1111/j.1755-0998.2009.02739.x.

Kim EB, Lee SR, Lee CIl, Park H, Kim HW. 2019. Development of the cephalopod-specific universal primer set and its application for the metabarcoding analysis of planktonic cephalopods in Korean waters. PeerJ 7: e7140. DOI: 10.7717/peerj.7140.

Kochzius M, Seidel C, Antoniou A, Botla SK, Campo D, Cariani A, Vazquez EG, Hauschild J, Hervet C, Hjörleifsdottir S, Hreggvidsson G, Kappel K, Landi M, Magoulas A, Marteinsson V, Nölte M, Plane S, Tinti F, Turan C, Blohm D. 2010. Identifying fishes through DNA barcodes and microarrays. PLoS One 5: e012620. DOI: 10.1371/journal.pone.0012620.

Li Y, Song J, Shen, X, Cai Y, Cheng H, Zhang X. 2019. The first mitochondrial genome of Macrobrachium rosenbergii from China: Phylogeny and gene rearrangement within Caridea. Mitochondrial DNA Part B Resour 4 (1) 134-136. DOI: 10.1080/23802359.2018.1540262.

Liu S, Xu K, Wu Z, Xie X, Feng J. 2016. Identification of five highly priced tuna species by quantitative real-time polymerase chain reaction. Mitochondrial DNA 27 (5): 3270-3279. DOI: 10.3109/19401736.2015.1015004.

Lopez I, Pardo MA. 2005. Application of relative quantification TaqMan real-time polymerase chain reaction technology for the identification and quantification of Thunnus alalunga and Thunnus albacares. J Agric Food Chem 53 (11): 4554-4560. DOI: 10.1021/jf0500841.

Lorenz TC. 2012. Polymerase chain reaction: Basic protocol plus troubleshooting and optimization strategies. J Vis Exp 63: e3998. DOI: $10.3791 / 3998$

Marko PB, Lee SC, Rice AM, Gramling JM, Fitzhenry TM, McAlister JS, Harper GR, Moran AL. 2004. Mislabelling of a depleted reef fish. Nature 430 (6997): 309-310. DOI: 10.1038/430309b.

Martinez I, Friis TJ. 2004. Application of proteome analysis to seafood authentication. Proteomics 4 (2): 347-354. DOI: 10.1002/pmic. 200300569

Merritt TJS, Shi L, Chase MC, Rex MA, Etter RJ, Quattro JM. 1998. Universal cytochrome $b$ primers facilitate intraspecific studies in molluscan taxa. Mol Mar Biol Biotechnol 7 (1): 7-11.

Miller AD, Murphy NP, Burridge CP, Austin CM. 2005. Complete mitochondrial DNA sequences of the decapod crustaceans Pseudocarcinus gigas (Menippidae) and Macrobrachium rosenbergii 
(Palaemonidae). Mar Biotechnol 7 (4): 339-349. DOI: 10.1007/s10126-004-4077-8.

Miya M, Sato Y, Fukunaga T, Sado T, Poulsen JY, Sato K, Minamoto T, Yamamoto S, Yamanaka H, Araki H, Kondoh M, Iwasaki W. 2015. MiFish, a set of universal PCR primers for metabarcoding environmental DNA from fishes: Detection of more than 230 subtropical marine species. R Soc Open Sci 2: 150088. DOI: $10.1098 / \mathrm{rsos} .150088$

Mubarak SMH, Al-Koofee DAF, Radhi OA, Ismael JM, Al-Zubaidi ZF. 2020. An optimization and common troubleshooting solving in polymerase chain reaction technique. Syst Rev Pharm 11 (2): 427 436. DOI: $10.5530 /$ srp.2020.2.63.

$\mathrm{Ng}$ P, Wowor D. 2011. On the nomenclature of the palaemonid names Palaemon spinipes Desmarest, 1817, Palaemon spinipes Schenkel, 1902, and Macrobrachium wallacei. Zootaxa 2904 (May): 66-68. DOI: 10.11646/zootaxa.2904.1.3.

Nicolè S, Negrisolo E, Eccher G, Mantovani R, Patarnello T, Erickson DL, Kress, WJ, Barcaccia G. 2012. DNA barcoding as a reliable method for the authentication of commercial seafood products. Food Technol Biotechnol 50 (4): 387-398.

Pearson WR. 2013. An introduction to sequence similarity ("Homology") searching. Curr Protoc Bioinformatics 1 (10): 1286-1292. DOI 10.1002/0471250953.bi0301s42.

Pepe T, Trotta M, Marco IDI, Cennamo P, Anastasio A, Cortesi ML. 2005. Mitochondrial cytochrome b DNA sequence variations: An approach to fish species identification in processed fish products. Food Prot 68 (2): 421-425. DOI: 10.4315/0362-028X-68.2.421.

Promega Corporation. 2019. Technical Manual Wizard® Genomic DNA Purification Kit Wizard ${ }^{\circ}$ Genomic DNA Purification Kit. Technical Bulletin 1-19. www.promega.com

Quellhorst G, Rulli S. 2012. A systematic guideline for developing the best real-time PCR primers Lessons learned from designing assays for more than 14,000 genes. Qiagen 1-9.

Radulovici AE, Archambault P, Dufresne F. 2010. DNA barcodes for marine biodiversity: Moving fast forward? Diversity 2 (4): 450-472. DOI: $10.3390 / \mathrm{d} 2040450$.

Rasmussen Hellberg RS, Morrissey MT. 2011. Advances in DNA-based techniques for the detection of seafood species substitution on the commercial market. J Lab Autom 16 (4): 308-321. DOI: 10.1016/j.jala.2010.07.004

Richardson DE, Vanwye JD, Exum AM, Cowen RK, Crawford DL. 2007. High-throughput species identification: From DNA isolation to bioinformatics: Technical article. Mol Ecol Notes 7 (2): 199-207. DOI: $10.1111 / \mathrm{j} .1471-8286.2006 .01620 . x$

Roche Diagnostics. 2006. PCR Applications Manual $3^{\text {rd }}$ Edition. Evolution.

Sevilla RG, Diez A, Norén M, Mouchel O, Jérôme M, Verrez-Bagnis V, Van Pelt H, Favre-Krey L, Krey G, Bautista JM. 2007. Primers and polymerase chain reaction conditions for DNA barcoding teleost fish based on the mitochondrial cytochrome $b$ and nuclear rhodopsin genes. Mol Ecol Notes 7 (5): 730-734. DOI: 10.1111/j.14718286.2007.01863.x.

Sharma L, Watts E, Singh P. 2020. High resolution real-time PCR melting curve assay for identification of top five Penaeidae shrimp species. LWT 133: 109983. DOI: 10.1016/j.lwt.2020.109983.

Skibinski DOF, Gallagher C, Beynon CM. 1994. Sex-limited mitochondrial DNA transmission in the marine mussel Mytilus edulis. Genetics 138 (3): 801-809. DOI: 10.1093/genetics/138.3.801.

Tamura K, Nei M, Kumar S. 2004. Prospects for inferring very large phylogenies by using the neighbor-joining method. Proc Nat Acad Sci USA 101 (30): 11030-11035. DOI: 10.1073/pnas.0404206101.

Taylor SC, Laperriere G, Germain H. 2017. Droplet Digital PCR versus qPCR for gene expression analysis with low abundant targets: From variable nonsense to publication quality data. Sci Rep 7 (1): 2409. DOI: $10.1038 / \mathrm{s} 41598-017-02217-\mathrm{x}$.

Teletchea F. 2009. Molecular identification methods of fish species: Reassessment and possible applications. Rev Fish Biol Fish 19 (3): 265-293. DOI: 10.1007/s11160-009-9107-4.

Thermo Scientific. 2019. NanoDrop 1000 Spectrophotometer V3.8 User's Manual.

Ward RD, Zemla TS, Innes BH, Last PR, Hebert, PDN. 2005. DNA barcoding Australia's fish species. Philos Trans R Soc Lond B Biol Sci 360 (1462): 1847-1857. DOI: 10.1098/rstb.2005.1716.

Zanzi A, Martinsohn JT. 2017. FishTrace: A genetic catalogue of European fishes. Database (Oxford) 2017: bax075. DOI: 10.1093/database/bax075. 